\title{
Interventional radiology preparedness during coronavirus disease (COVID-19) pandemic
}

\author{
Tushar Garg, Ajinkya Desai, Kunal Gala², Gireesh Warawdekar³, Sidhartha Tavri \\ Department of Radiology, Seth GS Medical College and KEM Hospital, ${ }^{2}$ Department of Radiodiagnosis, Tata Memorial Centre, \\ Homi Bhabha National Institute, ${ }^{3}$ Department of Radiology, Lilavati Hospital and Research Center, Mumbai, Maharashtra, \\ India, 'Department of Radiology, University of Mississippi Medical Center, MS, ${ }^{4}$ Department of Radiology, University Hospitals \\ Cleveland Medical Center, Case Western Reserve School of Medicine, $\mathrm{OH}$, USA
}

Correspondence: Dr. Sidhartha Tavri, Division of Vascular and Interventional Radiology, Department of Radiology, University Hospitals Cleveland Medical Center, Case Western Reserve School of Medicine, 11100 Euclid Ave, BSH 5056, Cleveland, OH 44106, United States. E-mail: Sidhartha.Tavri@UHHospitals.org

\begin{abstract}
The COVID-19 pandemic has affected every sector of healthcare. Interventional Radiology in many instances continues to provide frontline care during this pandemic. The purpose of this article is to assist Interventional Radiologists in their preparation to face the challenges, by summarizing global experiences and guidelines. We provide a basic framework that can be used to prepare institue specific guidelines in coordination with multidisciplinary teams and hospital administration.
\end{abstract}

Key words: COVID-19; interventional radiology; pandemic

\section{Introduction}

Severe acute respiratory syndrome coronavirus 2 (SARS-CoV-2) causes coronavirus disease (COVID-19). On March $11^{\text {th }}$ 2020, World Health Organization (WHO) labelled this disease a pandemic. As the prevalence of this disease increases, significant logistical, economical and infrastructural challenges are posed to the health care systems. At the time of writing this article, 173,763 cases and 4,971 deaths have been reported due to COVID-19 and its complications in India. ${ }^{[1]}$ Radiology departments around the world have instituted policies and algorithms for preparedness ${ }^{[2]}$ Apart from the Ultrasound and CT technologists, Interventional Radiology (IR) staff is on the frontline as well. Therefore, it is crucial to develop and implement guidelines that will help limit cross transmission to protect patients and health care workers (HCWs) from

\begin{tabular}{|c|c|}
\hline \multicolumn{2}{|c|}{ Access this article online } \\
\hline Quick Response Code: & \\
\hline \multirow{2}{*}{ 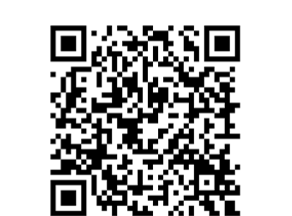 } & $\begin{array}{l}\text { Website: } \\
\text { www.ijri.org }\end{array}$ \\
\hline & $\begin{array}{l}\text { DOI: } \\
\text { 10.4103/ijri.IJRI_442_20 }\end{array}$ \\
\hline
\end{tabular}

being infected while optimizing resource utilization. This article is meant to serve as a reference and has been prepared by utilizing various international society and institutional guidelines that were prepared and used in the early phases of this pandemic before India witnessed its first case. The overarching goal of this article is to highlight the top ten things Interventional Radiology departments in India should know and prepare for during the COVID-19 pandemic.

\section{SARS-CoV-2 Basic Virology and Transmission}

Coronavirus group consists of large, enveloped, positive-strand RNA viruses, which have four genera:

This is an open access journal, and articles are distributed under the terms of the Creative Commons Attribution-NonCommercial-ShareAlike 4.0 License, which allows others to remix, tweak, and build upon the work non-commercially, as long as appropriate credit is given and the new creations are licensed under the identical terms.

For reprints contact: WKHLRPMedknow_reprints@wolterskluwer.com

Cite this article as: Garg T, Desai A, Gala K, Warawdekar G, Tavri S. Interventional radiology preparedness during coronavirus disease (COVID-19) pandemic. Indian J Radiol Imaging 2021;31:S21-30.

Received: 31-May-2020

Accepted: 05-Jul-2020

Revised: 20-Jun-2020

Published: 23-Jan-2021 
alpha, beta, delta, and gamma, of which alpha and beta genera viruses are known to infect humans. ${ }^{[3]}$ This group of virus was thought to infect only animals until 2002 when it caused a severe acute respiratory syndrome (SARS) outbreak in Guangdong, China, due to infection by SARS-CoV. ${ }^{[4]}$ In December 2019, a cluster of pneumonia cases caused by a newly identified beta-coronavirus occurred in Wuhan, China. This virus was named as the Severe acute respiratory syndrome coronavirus 2 (SARS-CoV-2), and the disease as Coronavirus disease 19 (COVID-19). ${ }^{[5]}$ While still unconfirmed, it is theorized that the virus may have been transmitted from bats to humans via an intermediate host, likely birds or animals that are consumed as meat. Once transmitted, the virus infects humans by binding to the angiotensin-converting enzyme 2 (ACE-2) via its S protein. The ACE-2 receptor is present in abundance in the lower respiratory tract of humans, more specifically on the alveolar epithelial cells, which would explain the predominant respiratory manifestations of COVID-19. ${ }^{\left[{ }^{[]}\right.}$

Human-to-human transmission of COVID-19 occurs through exposure to the virus via one (or all) of three transmission routes that have been described so far; viz. droplet, contact and aerosol. ${ }^{[7]}$ Droplet transmission occurs when an individual near an infected person inhales or ingests respiratory droplets produced while coughing or sneezing. Contact transmission occurs when a person touches their mouth, nose or eyes after touching a contaminated surface (known as "fomite"), and aerosol transmission occurs when aerosols are formed by mixing of respiratory droplets into the air, and they are inhaled in high dose into the lungs in a relatively closed environment. SARS-CoV-2 has been found to remain viable on fomites for up to 72 hours after contamination, thus making it highly transmissible and virulent. ${ }^{[8]}$

\section{COVID-19 Clinical and Imaging Features}

\section{Clinical findings}

Following exposure to COVID-19, most individuals exhibit symptoms within four to five days, but the incubation period for COVID-19 can be up to fourteen days. ${ }^{[9]}$ The spectrum of clinical symptoms in infected individuals ranges from mild to critical, with most infections being mild. ${ }^{[10]}$ The most frequent serious manifestation of infection is pneumonia, which presents with fever, cough, dyspnea, and bilateral chest infiltrates on imaging. Other less frequent symptoms include upper respiratory tract infections, myalgias, diarrhoea, and loss of smell or taste. ${ }^{[11]}$ In a report published by the Chinese Center for Disease Control and Prevention, which analysed approximately 44,500 confirmed cases, mild disease (no or mild pneumonia) was seen in $81 \%$ of patients, severe disease (with dyspnea, hypoxia, or $>50 \%$ lung involvement on imaging within 24 to 48 hours) was reported in $14 \%$ of patients, and critical disease (with respiratory failure, shock, or multiorgan failure) was reported in $5 \%$ of patients. ${ }^{[10]}$ The overall case-fatality rate was reported as $2.3 \%$, with higher fatality amongst those with advanced age and underlying medical comorbidities. ${ }^{[10]}$

\section{Imaging findings}

Imaging is being used as an adjunctive tool to grade the severity of disease in COVID-19 patients. As per the American College of Radiology (ACR), imaging, specifically chest $\mathrm{CT}$, should not be used for screening or diagnosis. Many characteristic imaging findings of COVID-19 have been described on chest radiograph and CT. Typical abnormal CT findings include bilateral, peripheral, and lower lung predominant ground glass opacities and consolidation as well as 'crazy-paving' pattern secondary to intralobular septal thickening. ${ }^{[12]}$ Radiographic findings can be non-specific and should be correlated with the patient's history and symptoms. The Radiological Society of North America (RSNA) has categorized CT features for COVID-19 into typical, indeterminate, or atypical for reporting purposes. ${ }^{[13]}$

\section{COVID 19 - Case Definitions, Testing, Contact Tracing}

The case definitions and contact categorizations released by the National Center of Disease Control, Ministry of Health and Welfare (MoHFW), Government of India (GOI) based on the World Health Organization data are described in Table 1. ${ }^{[14]}$

COVID-19 is diagnosed by the detection of SARS-CoV-2 RNA with the help of nuclear acid amplification tests (NAATs) by collecting nasopharyngeal or oropharyngeal swabs. Testing in India is being performed by various government and private testing laboratories, which have been approved by the Indian Council of Medical Research (ICMR) as testing centres. Indian Council of Medical Research (ICMR) and MoHFW have provided various guidelines for testing on their website and they are regularly updated. These guidelines describe strategies for testing of COVID-19 in India by molecular-based tests like reverse transcriptase-polymerase chain reaction (RT-PCR), TruNat and Cartridge-based NAAT or rapid antibody tests. ${ }^{[15]}$ The false negative rate for SARS-CoV-2 RT-PCR is highly variable, it is highest within first 5 days after exposure (up to $67 \%$ ) and lowest on day 8 after exposure (21\%). ${ }^{16]}$ The antibody test is still not available in India but they are expected to be available soon.

All individuals staying in containment zones are triaged as COVID-19 positive patients, unless proved otherwise, and therefore when managing these patients precautions similar to management of COVID-19 positive patients should be taken. 
Table 1: Case definitionand contact definition

\begin{tabular}{|c|c|}
\hline & Definitions \\
\hline $\begin{array}{l}\text { Suspected } \\
\text { Case }\end{array}$ & $\begin{array}{l}\text { A patient with acute respiratory illness \{fever and at } \\
\text { least one sign/symptom of respiratory disease (e.g., } \\
\text { cough, shortness of breath)\}, AND a history of travel to } \\
\text { or residence in a country/area or territory reporting local } \\
\text { transmission of COVID-19 disease during the } 14 \text { days } \\
\text { prior to symptom onset; } \\
\text { OR } \\
\text { A patient/Health care worker with any acute respiratory } \\
\text { illness AND having been in contact with a confirmed } \\
\text { COVID-19 case in the last } 14 \text { days prior to onset of } \\
\text { symptoms; } \\
\text { OR } \\
\text { A patient with severe acute respiratory infection }\{\text { fever } \\
\text { and at least one sign/symptom of respiratory } \\
\text { disease (e.g., cough, shortness breath)\} AND requiring } \\
\text { hospitalization AND with no other etiology that fully } \\
\text { explains the clinical presentation; } \\
\text { OR } \\
\text { A case for whom testing for COVID-19 is inconclusive }\end{array}$ \\
\hline $\begin{array}{l}\text { Confirmed } \\
\text { Case }\end{array}$ & $\begin{array}{l}\text { A person with laboratory confirmation of COVID- } 19 \\
\text { infection, irrespective of clinical signs and symptoms. }\end{array}$ \\
\hline $\begin{array}{l}\text { Contact } \\
\text { Definition }\end{array}$ & $\begin{array}{l}\text { Providing direct care without proper personal protective } \\
\text { equipment (PPE) for COVID-19 patients } \\
\text { OR } \\
\text { Staying in the same close environment of a } \\
\text { COVID-19 patient (including workplace, classroom, } \\
\text { household, gatherings). } \\
\text { OR } \\
\text { Traveling together in close proximity }(1 \mathrm{~m}) \text { with a } \\
\text { symptomatic person who later tested positive for } \\
\text { COVID-19 }\end{array}$ \\
\hline
\end{tabular}

Aarogya Setu app

Aarogya Setu app is an open-source "contact tracing, syndrome mapping and self-assessment" digital service which is development by the National Informatics Center under the Ministry of Electronics and Information Technology. The purpose of the application is to increase awareness about COVID-19 and help connect healthcare-related services to everyone who downloads the application. The application works by using the GPS and Bluetooth features in the phone to track the coronavirus infection. With the help of both of these tools, it can determine if one has been near (within six feet of) a COVID-19 infected person by scanning through a database of known cases across India. The application stratifies the risk of contracting COVID-19 infection to the user (user status), helps the user identify COVID-19 symptoms, access their risk profile (self-assessment), provides COVID-19 updates and helps with E-pass application and integration. ${ }^{[17]}$

\section{Protection of Patient in Hospitals Screening and Segregation}

Health care workers and admitted patients are at very high risk of contracting COVID-19 from infected COVID-19 patients. Healthcare facilities must establish strict protocols to ensure safety of these "at risk" individuals. In order to minimize risk of transmission in this susceptible population, health care workers, staff and visitors entering the hospital should undergo thermal screening. Thermal screening is done by hand-held thermal scanner before entering the hospital, and if they are found to be febrile, they should be isolated and sent to either fever Outpatient Department (OPD) or referred to the nearest COVID-19 centre if they cannot be not treated in same hospital. After an initial thermal screening is done, the next step is proper hand sanitization before a person can enter the hospital as the transmission of COVID-19 can occur by contact; temporary hand wash and sanitization stands can be set-up at the entrance of hospitals for this purpose, where patients and staff can wash their hands according to the hand hygiene technique described by WHO. A written or pictorial description of this technique should be displayed above the washing stations. Various informational posters regarding symptoms of COVID-19, personal hygiene and sanitation of hands can also be put up along the walls of the hospital to provide easy access of information to patients. Next, the patient is allowed to enter the hospital and they will encounter an IR reception which is set up for preliminary health screening, which include a thorough COVID-19 history, for which patients should be asked about classic respiratory symptoms (fever, dry cough and shortness of breath), exposure history, travel history, contact history and area of residence if there is community transmission. COVID-19 testing should be available and performed for all patients who meet criteria per institutional guidelines. When possible, Inpatients and Outpatients can be segregated to prevent cross transmission [Table 2].

\section{Protection of IR Staff PPE, Hygiene, and Segregation}

IR staff (physicians, nurses, technologists) directly caring for patients are at high risk of contracting the infection. All patients coming into the IR department should be screened for COVID -19 symptoms as mentioned above. For inpatients, this information should be available in the patient's chart. For outpatients, screening should occur in a designated area in the IR department, ideally adequately segregated from the shared working space. Patients who screen positive for COVID-19 symptoms should be re-scheduled, unless undergoing emergent procedures. They should be re-directed to appropriate COVID-19 centres for additional tests and management.

The risk of infection amongst IR staff can be mitigated by wearing appropriate personal protective equipment (PPE) when interacting with patients. All IR staff must be trained to appropriately don, doff and dispose of the PPE, which includes masks, eye protection, gloves, gowns, caps, and shoe-covers during treatment of COVID-19 patients. PPE should be judicially used to avoid shortage in times of greater need. 
Another effective strategy to minimize the risk of cross-infection is the segregation of staff members. Segregation can be temporal or physical/spatial [Table 2]. In the outpatient area, all patients should wear masks as it is mandatory in India, and they must maintain a distance of at least one meter. Any IR staff sitting in the outpatient should wear N95 mask, a shield and gloves.

\section{PPE masks}

There are various types of masks available for use. These include cloth masks, surgical masks and N95 masks. Filtering facepiece (FFP 2/3) and N95 are high performing filtering masks recommended for the high-risk situations. The superior quality filtration is achieved by a combination of a web of polypropylene microfibers and electrostatic charge. The N95 designation means that under test conditions, the respirator blocks at least $95 \%$ of solid and liquid aerosol test particles. These masks do not work unless they fit well over the face and create a seal. Therefore, individual mask testing should be undertaken before they are worn on clinical duty. WHO recommends FFP 2/3 and N95 masks, if undamaged, can be used for up to 4 hours. ${ }^{[18]}$ Type of masks that need to be used is geographic and based on institutional availability and guidelines. Cross-transmission is minimized to great extent when both the patients and providers wear masks as opposed to one or the other. The recommended PPE measures to be used in different scenarios are mentioned in Table 3. ${ }^{[19-21]}$

All India Institute of Medical Sciences (AIIMS) has published guidelines for the extended use of $\mathrm{N}-95$ masks for the personal safety of health care workers (HCWs). As per the guidelines, every HCW is provided with four N-95 masks in four labelled brown bags. On day 1, the HCW should use mask 1 . At the end of their shift, they should place the mask in paper bag 1 and let it dry for 4 days. For the following three consecutive days, the same protocol needs to be followed with the remaining 3 masks, after which mask number 1 can be reused on the fifth day. This protocol needs to be repeated until all four masks have been used 5 times. This helps prevent shortage of N-95 masks and increases the efficiency of their use. ${ }^{[20]}$

Another effective strategy to preserve N95 masks is using the surgical masks to cover it. The surgical mask can be discarded allowing reuse of the N95. A face shield is recommended apart from eye protection for protection. For aerosol generating procedures, PAPR is recommended, if available.

\section{Classification of IR Procedures on the Basis of Acuity}

As the number of COVID-19 cases increases and with the subsequent rise in the number of COVID-19 related hospitalizations, IR departments will have to re-schedule elective and nonurgent cases to decrease the risk of cross-transmission and preserve PPE and hospital beds. Elective procedures can be postponed by 1 to 3 months depending on local factors. Several factors are considered to determine the acuity of a procedure viz. clinical status

Table 2: Methods for segregation of patients and staff

\begin{tabular}{lll}
\hline & Segregation by Time & Segregation by Space \\
\hline For Patients & Outpatient and In-patient procedures at different times & Outpatient and in-patient procedures in different IR suites \\
& COVID and Non-COVID patient procedures in different IR suites \\
$\begin{array}{l}\text { For Health Care } \\
\text { Providers }\end{array}$ & $\begin{array}{l}\text { Making different teams containing physician, technologists and } \\
\text { Kurses } \\
\text { Keeping on and off days for different teams, e.g., one team will work }\end{array}$ & $\begin{array}{l}\text { Reducing the number of procedures done by trainees to } \\
\text { minimizing the number of people involved in the procedures }\end{array}$ \\
& & Creating separation in the work-space to allow the \\
& maintenance of proper social distancing & Creating break rooms for staff
\end{tabular}

Table 3: PPE Recommendations for different scenarios

\begin{tabular}{|c|c|c|c|}
\hline Scenario & Activity & Risk & Recommended PPE \\
\hline Thermal screening station at the point of entry & $\begin{array}{l}\text { Record temperature with a handheld thermal } \\
\text { recorder }\end{array}$ & Moderate risk & $\begin{array}{l}\text { N95/Triple-layer surgical } \\
\text { mask } \\
\text { Gloves }\end{array}$ \\
\hline Holding area/waiting area & $\begin{array}{l}\text { Doctors, nurses/paramedics interacting with the } \\
\text { patients }\end{array}$ & Low risk & No PPE required \\
\hline Non-COVID-19 patients & Aerosol generating IR procedures & High Risk & ${ }^{*}$ Full PPE \\
\hline $\begin{array}{l}\text { Patients with pneumonia or acute respiratory } \\
\text { symptoms }\end{array}$ & Non-procedural contact & Moderate Risk & $\begin{array}{l}\text { N95/Triple-layer surgical } \\
\text { mask } \\
\text { Gloves }\end{array}$ \\
\hline $\begin{array}{l}\text { Patients with pneumonia or acute respiratory } \\
\text { symptoms }\end{array}$ & IR Procedure & High Risk & ${ }^{*}$ Full PPE \\
\hline Confirmed or suspected COVID-19 patients & Any activity & High Risk & ${ }^{*}$ Full PPE \\
\hline Confirmed or suspected COVID-19 patients & Aerosol generating IR procedures & High Risk & Full complement of PPE \\
\hline
\end{tabular}

*Full PPE - fit tested N95 ot PAPR; surgical mask, eye shield, gown, gloves, shoe covers 
of the patient, any associated comorbidities, disease state, clinical impact of delaying the procedure, etc., The Society of Interventional Radiology COVID-19 Taskforce has developed an Interventional Radiology-Procedure Acuity Scale, which has been adapted and described in Table 4. ${ }^{[21]}$

In India during the first phase of lockdown the Government had advised to postpone all the procedures for 21 days and to carry out only emergency procedure. From second phase of the lockdown cancer care can be carried out as it is in semi-emergency procedures.

\section{Classification of IR Procedures Based on Aerosol Generating Potential (AGP)}

It is essential for all personnel involved in patient care to be familiar with AGPs. Routine surgical masks do not protect against aerosols and therefore it is imperative to use appropriate PPE while performing these AGPs. An AGP is defined as any procedure that irritates the respiratory tract resulting in the generation and dispersal of aerosols. ${ }^{[22]}$ Coughing causes droplet transmission at the least, however some categorize it as AGP for the purpose of PPE utilization.

Table 4: Interventional Radiology-Procedure Acuity Scale (Adapted from COVID-19 Toolkit Society of Interventional Radiology)

\begin{tabular}{|c|c|c|c|}
\hline $\begin{array}{l}\text { Disease/ } \\
\text { Pathology }\end{array}$ & $\begin{array}{l}\text { Tier } 1 \\
\text { Postpone Procedure }\end{array}$ & $\begin{array}{l}\text { Tier } 2 \\
\text { Postpone procedure if possible }\end{array}$ & $\begin{array}{l}\text { Tier } 3 \\
\text { Do not postpone }\end{array}$ \\
\hline $\begin{array}{l}\text { Fluid } \\
\text { collections }\end{array}$ & Routine tube/drain change & $\begin{array}{l}\text { Percutaneous collection drainage for } \\
\text { infection without septic shock if the } \\
\text { antibiotic trial fails }\end{array}$ & $\begin{array}{l}\text { Percutaneous fluid collection drainage for } \\
\text { infection in a patient with septic shock }\end{array}$ \\
\hline Biopsies & $\begin{array}{l}\text { Thyroid biopsy } \\
\text { Liver biopsy for abnormal LFTs }\end{array}$ & Biopsy for possible cancer diagnosis & Transplant rejection solid organ biopsy \\
\hline $\begin{array}{l}\text { Reproductive } \\
\text { tract } \\
\text { interventions }\end{array}$ & $\begin{array}{l}\text { Fallopian tube recanalization } \\
\text { Hysterosalpingogram } \\
\text { Uterine fibroid embolization } \\
\text { Prostate artery embolization } \\
\text { Pelvic congestion embolization }\end{array}$ & - & - \\
\hline $\begin{array}{l}\text { Urinary tract } \\
\text { interventions }\end{array}$ & $\begin{array}{l}\text { Percutaneous access for } \\
\text { nephrolithotomy in conjunction with } \\
\text { urology } \\
\text { RCC ablation (cryo/RF/microwave) }\end{array}$ & $\begin{array}{l}\text { Nephrostomy tube change for malfunction } \\
\text { or leakage }\end{array}$ & Percutaneous nephrostomy for septic shock \\
\hline $\begin{array}{l}\text { Hepatobiliary } \\
\text { interventions }\end{array}$ & TIPS for ascites & $\begin{array}{l}\text { Locoregional therapy for hepatobiliary } \\
\text { cancer }\end{array}$ & $\begin{array}{l}\text { Percutaneous cholecystostomy/biliary drain for } \\
\text { septic shock }\end{array}$ \\
\hline $\begin{array}{l}\text { Peripheral } \\
\text { artery disease }\end{array}$ & $\begin{array}{l}\text { Peripheral angiogram and } \\
\text { interventions for claudication }\end{array}$ & $\begin{array}{l}\text { Peripheral angiogram and intervention for } \\
\text { chronic limb-threatening ischemia }\end{array}$ & $\begin{array}{l}\text { Arterial lysis/thrombectomy for acute limb } \\
\text { ischemia } \\
\text { PAD for Limb ischemia: progressive tissue loss, acute } \\
\text { limb ischemia Intravascular management of PAD } \\
\text { leading to acute limb ischemia }\end{array}$ \\
\hline $\begin{array}{l}\text { Arterial } \\
\text { aneurysms }\end{array}$ & $\begin{array}{l}\text { Endovascular aneurysm repair for } \\
\text { abdominal aneurysm less than } 6.5 \\
\mathrm{~cm}\end{array}$ & $\begin{array}{l}\text { Endovascular aneurysm repair for abdominal } \\
\text { aortic aneurysm more than } 6.5 \mathrm{~cm} \text { and thoracic } \\
\text { aortic aneurysm more than } 6.5 \mathrm{~cm} \\
\text { Endovascular management of asymptomatic } \\
\text { peripheral and non-aortic intraabdominal } \\
\text { aneurysms }\end{array}$ & $\begin{array}{l}\text { Endovascular aneurysm repair/thoracic } \\
\text { endovascular aortic repair for symptomatic or } \\
\text { ruptured abdominal aortic aneurysm or thoracic } \\
\text { aortic aneurysm } \\
\text { Endovascular management of symptomatic peripheral } \\
\text { and non-aortic intraabdominal aneurysms } \\
\text { Endovascular management of pseudoaneurysms }\end{array}$ \\
\hline $\begin{array}{l}\text { Venous/ } \\
\text { Dialysis } \\
\text { Access } \\
\text { Interventions }\end{array}$ & $\begin{array}{l}\text { Asymptomatic or mildly symptomatic } \\
\text { May-Thurner syndrome } \\
\text { IVC filter removal } \\
\text { Varicose veins } \\
\text { Venous sampling } \\
\text { Central venous catheter/port } \\
\text { removals for completion of treatment }\end{array}$ & $\begin{array}{l}\text { Venous thoracic outlet syndrome intervention } \\
\text { for mild symptoms } \\
\text { Massive iliofemoral DVT without phlegmasia } \\
\text { Venous intervention for ulcers in lower } \\
\text { extremity } \\
\text { IVC filter placement in low-risk patients } \\
\text { Fistula/Dialysis access interventions for } \\
\text { suboptimal function } \\
\text { Central Venous Catheter or PICC line } \\
\text { placement }\end{array}$ & $\begin{array}{l}\text { Fistula/Dialysis access interventions for } \\
\text { thrombosis }\end{array}$ \\
\hline $\begin{array}{l}\text { Bleeding or } \\
\text { ischemia }\end{array}$ & & & $\begin{array}{l}\text { Trauma interventions } \\
\text { Pulmonary embolism therapy } \\
\text { Stroke Interventions } \\
\text { Symptomatic carotid artery stenosis } \\
\text { interventions } \\
\text { Acute hemorrhage interventions } \\
\text { EVAR/TEVAR for dissection with rupture and/or } \\
\text { malperfusion } \\
\text { Symptomatic acute mesenteric ischemia } \\
\text { intervention }\end{array}$ \\
\hline
\end{tabular}


Commonly performed AGPs, as described on the SIR COVID Toolkit are listed in Table 5. ${ }^{[23]}$

\section{IR Workflow Modifications}

All request for IR procedures for suspected or confirmed COVID-19 patients' needs to be vetted before scheduling the procedure. Non-emergent procedures may be postponed until the patient is deemed negative on testing.

\section{Location}

The primary goal is to minimize cross-transmission by avoiding patient transfer. For COVID positive patients, when possible, procedures should be performed bedside by using ultrasound. ${ }^{[24]}$ These procedures could include pleural fluid and ascites drainage, superficial abscess and gallbladder drainage, venous access, etc., If the procedure cannot be performed at the bedside due to their complexity or the need for angiography or fluoroscopy (C-Arm), it should be performed in designated angiography suites or OT complexes after strict decontamination. Certain procedures can be performed in OT complexes with C-arm guidance like nephrostomy or percutaneous biliary drainage. Higher and more complex procedures like angiography for bleeding, stroke, thrombolysis etc., should only be reserved in designated angiography suites. Portable ultrasound utilized should undergo thorough decontamination process before it leaves the isolation room in which the procedure is performed. PPE donning and doffing protocols must be followed as well [Figures 1 and 2].

\section{Anaesthesia}

The minimally invasive nature of IR procedures allows most procedures to be done under local anaesthesia or moderate sedation. This helps avoid intubation for general anaesthesia, which is an AGP. If general anaesthesia is needed, patients should be intubated in a designated

Table 5: Aerosol generating procedures (Adapted from COVID-19 Toolkit Society of Interventional Radiology)

Any procedure in a patient who
Requires intubation/extubation
Is receiving a form of ventilatory support associated with the risk of
mechanical dispersal of aerosols
Requires active airway suctioning (i.e., tracheostomy patient)
Any procedure which can induce coughing
Lung biopsy
Lung ablation
Thoracentesis
Pleural drains
Chest tube for pneumothorax
Bronchial artery embolization
Bronchial stenting
Nasogastric Tube (NG tube) or Orogastric tube (OG tube) placement
Any procedure that requires NG tube placement:
Gastrostomy
Gastro-jejunostomy tube placement
Jejunostomy
Gl stent placement

area/room (which is not an IR procedure room), ideally a negative pressure room, with only the minimum number of required personnel in the room. Once the airway is secure, it is considered a closed system with a low risk of aerosol generation. The patient can then be brought into the IR procedure room. The ventilator should also be brought along with the patient so no cross transmission of infection can occur. If this is not possible, then intubation of the patient in IR suite can be done by one anaesthetist or as minimal staff as possible and room needs to be empty for 30 min after the intubation, to allow settlement of the aerosols generated.

\section{IR suite}

Consider designation of one IR suite as the COVID suite. If feasible, construction of negative pressure anteroom should be considered in conjunction with hospital engineers and environmental services. Anterooms are negative pressure compared to the adjacent hallways and typically vented to a HepaFilter. We recommend the preparation of a checklist akin to Universal protocol checklist for preparing procedure suites for a COVID positive or suspect patient. To prepare the suite for procedures, all non-essential items are removed from the suite, and all cabinets are locked and draped with disposable plastic sheets. Disposable plastic sheets are also draped over any other remaining equipment in the room. A mobile cabinet containing all essential equipment is kept just outside the suite for easy access. Before the patient enters the IR suite, there should be proper coordination between the staff in the isolation

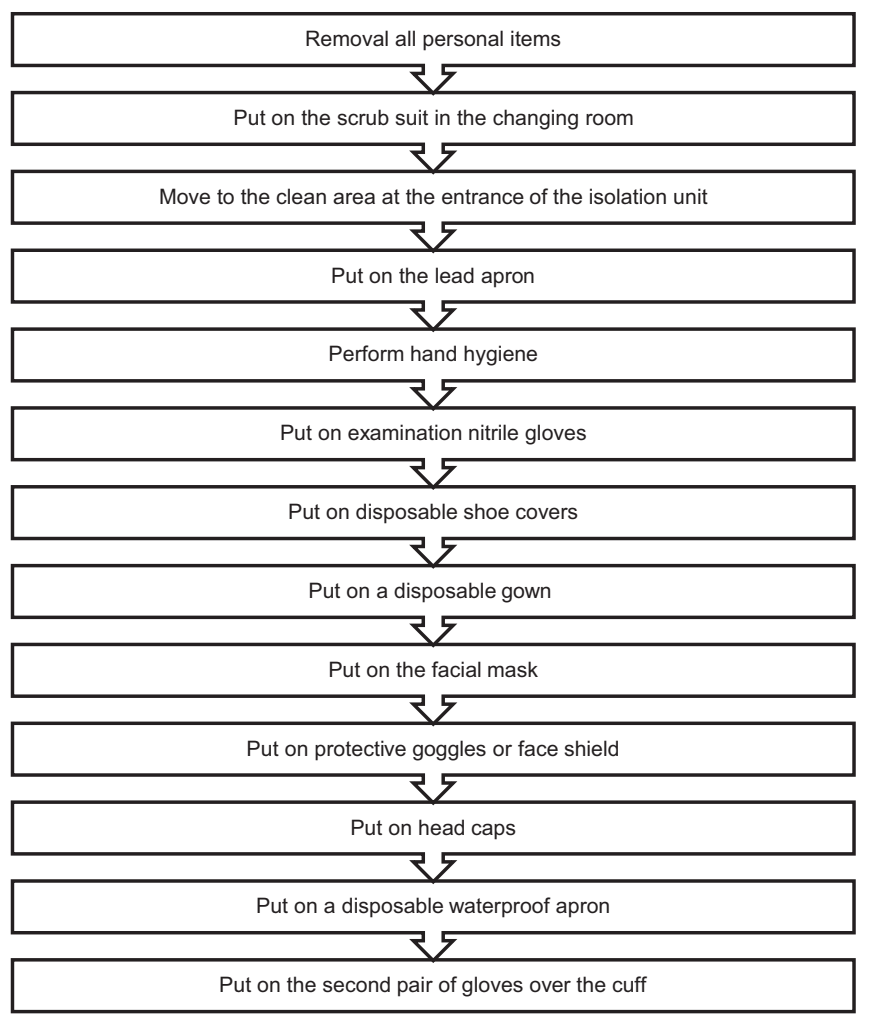

Figure 1: Sequence for putting on Personal Protective Equipment 


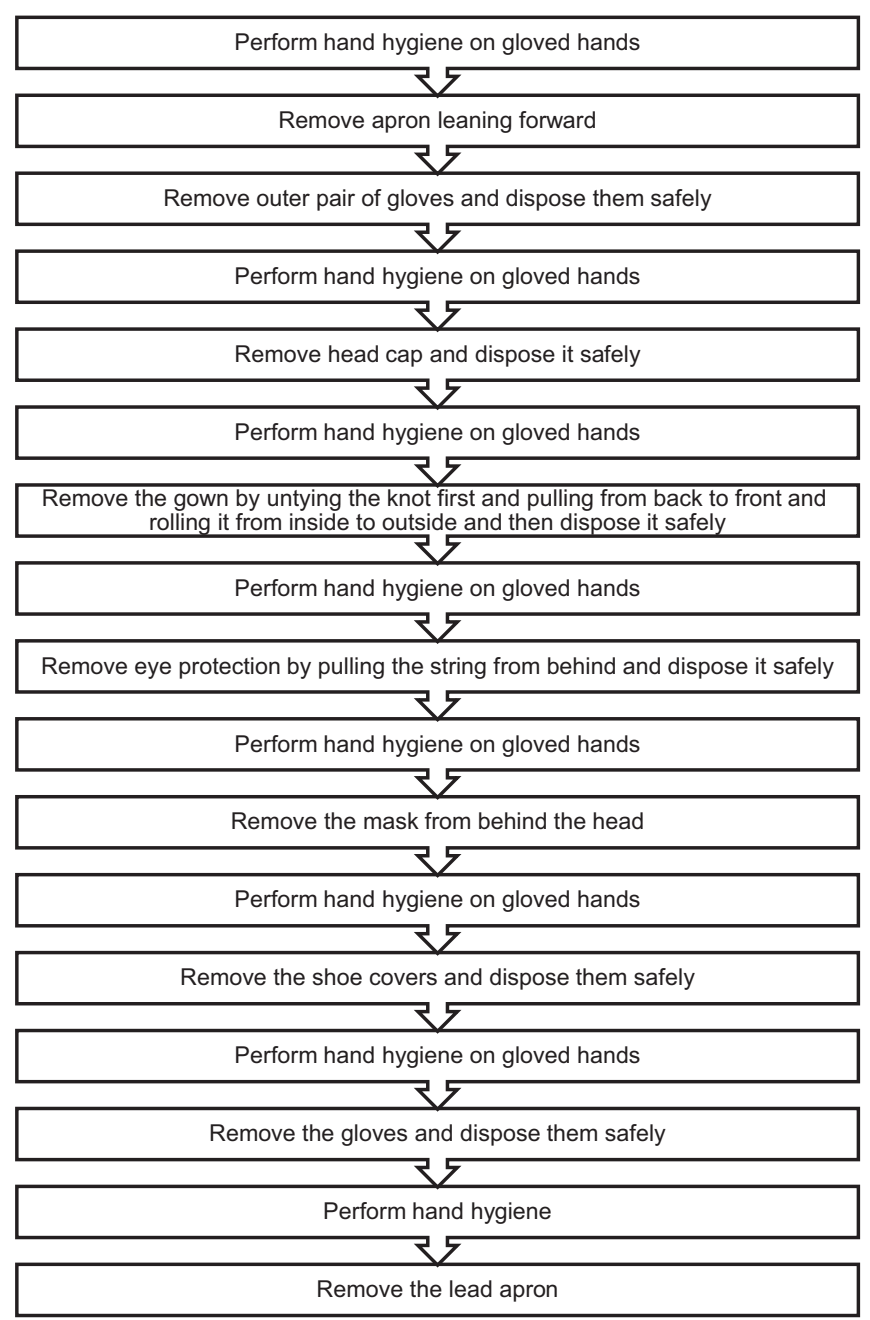

Figure 2: Sequence for removal of personal protective equipment

room and IR in-charge so that no patients or relative are in the adjacent hallways. The corridor should be vacated so as to prevent cross transmission. After this, the patient is brought directly into the IR suite. If intubation is required, it should be performed by an anaesthetist in a separate designated negative pressure room if available. If not, intubation can be performed in the IR procedure suite with only the required personnel in the room (anaesthesia team). Every member present in the room during intubation should wear appropriate PPE. The IR procedure is then performed as usual, with all involved team members wearing appropriate PPE and special emphasis on not leaving the room unless necessary. ${ }^{[25]}$ Ideally, a circulating IR tech should be available and present outside the room, to hand over any equipment/inventory, as needed. There should be as minimal staff during the procedure, if possible, to restrict the number of IR personnel to less than 4, which includes primary IR consultant, assisting personnel (if necessary), technologist and nurse. If fluid specimens are required to be send for analysis, the drainage system has to be closed and 3 way stop cork needs to be attached. Fluid is directly transferred into the container with proper labelling so no spillage occurs. Post-procedure, the patient should be shifted into a temporary recovery area after the procedure. The IR suite, along with the patient transfer path, should be decontaminated. ${ }^{[26]}$

Post procedure

After the patient exits the IR suite, removal of PPE and disposal of the waste is performed in designated spaces. Cleaning needs to be carried out after the procedure and cleaning staff must wear PPE kit. Cleaning of the floors should be with disinfectant (1:40 diluted bleach, sodium hypochlorite $1 / 1000 \mathrm{ppm}$ ). Immediately the room must be ventilated for 30-60 min and another $30 \mathrm{~min}$ the door must be closed. Exposed surfaces of the angiography suite which includes monitors, keyboard or consoles must be cleaned with ethanol with $70 \%$ or chlorhexidine -ethanol wipes. ${ }^{[27]}$

In most hospitals, under normal circumstances, the IR service would round on patients admitted for observation. However, with increasing COVID-19 related hospitalizations, the risk of contracting infection increases with increased patient interaction. Therefore, rounding should be avoided as far as possible, and if necessary, only the one physician taking care of the patient should conduct rounds instead of the whole team. Confirmed, probable, and suspected COVID-19 patients are admitted in isolation rooms and wards during their hospitalization, whereas patients who have tested negative for COVID-19 can stay in regular wards.

\section{Triage and Prioritize the Re-Scheduling of Postponed Procedures}

A sustained reduction in the rate of new COVID19 cases for about 2 weeks is required prior to rescheduling the previously postponed cases. Adequate PPE must be available as well. If lead time is available, it must be utilized to organize the backlog of cases, consider repeat imaging as necessary and repeat phone consults with the patients if applicable. The Society of Interventional Radiology (SIR) has proposed a framework for prioritization of re-scheduling IR procedures based on a scoring system which helps stratify patients. Factors involved include acuity of the procedure, COVID-19 status of the patient, aerosol-generating potential of the procedure and the anticipated post-procedure in-hospital recovery duration [Table 6]. ${ }^{[28]}$ This can be adapted in accordance with local and institutional policies to triage rescheduling of patients.

\section{Role of IR in COVID-19}

The role of Interventional Radiologists in the management of COVID-19 patients is varied. It can range from simple venous access to more complex procedures such as pulmonary embolism and stroke interventions. A multi-disciplinary collaboration with different specialties 
Garg, et al:: IR department in COVID-19

Table 6: Point scale for re-scheduling of canceled IR procedures (Adapted from COVID-19 Toolkit Society of Interventional Radiology)

\begin{tabular}{|c|c|c|c|c|}
\hline & $\begin{array}{l}\text { Postponed } \\
\text { procedure acuity }\end{array}$ & COVID-19 Status & $\begin{array}{l}\text { Aerosol generating } \\
\text { potential }\end{array}$ & $\begin{array}{l}\text { Post-procedure } \\
\text { discharge }\end{array}$ \\
\hline 1 point & High & Known negative or recovered by CDC-test based strategy & Low & Outpatient \\
\hline 2 points & Intermediate & Unknown but asymptomatic without recent COVID-19 contact & Intermediate & 1-2 day hospital day \\
\hline 3 points & Low & COVID-19 test positive and now asymptomatic for & High & >2-day hospital stay \\
\hline
\end{tabular}

Priority Class A- 4 to 5 points- Schedule as soon as possible. Priority Class B- 6 to 7 points- Schedule after completion of class A procedures. Priority Class C- 8 to 9 points- Schedule after completion of class A and B procedures. Priority Class D- 10 to 12 points- Do not schedule these procedures at this time

like critical care, vascular medicine, haematologists, infectious disease is essential for the integration of IR services in the management of COVID-19 patients. Venous access, placement of distal perfusion catheters for extracorporeal membrane oxygenation, pleural fluid drainage, and peritoneal collection drainage are common procedures required in isolation wards that can be performed at the bedside by Interventional Radiologists. There are numerous reports, along with emerging evidence that COVID-19 patients are at increased risk of thromboembolic events, ${ }^{[29]}$ with improved overall survival with therapeutic anticoagulation. ${ }^{[30]}$ IR can offer assistance in this cohort of patients by offering thrombectomy/thrombolysis procedures, most notably for pulmonary embolisms and stroke.

The number of elective procedures and in-person clinic visits have decreased during this period, primarily due to the stay at home order by the government. However, web-based platforms can be set-up, where clinic visits can be conducted virtually, and patients' can be evaluated and managed remotely. The patients on follow up need to do virtual consultation or if any patient needs an opinion than virtual consultant is possible with the new guidelines by ICMR.

\section{Opportunity in the time of chaos}

Communication, control, improve morale

During this time of chaos and stress, it is essential to develop fluid communication channels that can be used for the rapid dissemination of essential information to all relevant staff. This can be done with the help of web-based platforms like WhatsApp (Menlo Park, California), which is used for sharing informal and nonconfidential information, and an encrypted messaging platform TigerConnect (Santa Monica, California), which can be used for sharing confidential information.

In these trying times, different strategies can be implemented to improve individual and team morale. These include workload redistribution, application of employee-friendly institutional policies in case they suffer from COVID-19 related illness, provision of free meals for all the staff, providing appropriate PPE, giving special attention to emotional and mental well-being and providing the IR staff with special social support by setting up peer support virtual connection groups. ${ }^{[31]}$
Increase awareness and education amongst the staff regarding the COVID-19. To boost the confidence, appreciating and encouraging them in the times of COVID infection to boost the morale.

\section{Telemedicine}

In USA, telemedicine has emerged as a valuable tool during this pandemic to continue providing clinical care to patients, without actually seeing them in person. A similar strategy can be replicated in India, in institutions that have the financial and logistical capacity to do so. The use of telemedicine provides the physician with an opportunity to evaluate and manage patients at home while minimizing their exposure to ill patients. Although there has been a significant increase in willingness amongst patients and providers to use telemedicine amid this pandemic, there are still some fundamental barriers that exist, such as lack of appropriate equipment (due to financial constraints), lack of awareness, lack of knowledge, etc., However, telemedicine in IR will have a role even after the pandemic.

\section{Virtual education}

Due to the need for social distancing measures, traditional trainee-faculty teaching and in-person didactic lectures are not possible. This has been replaced by virtual live video conferences, where interested trainees and physicians can join these video lectures and learn about a particular topic. ${ }^{[32]}$ To make these video conferences more exciting and to increase participation, the use of integrated audience response systems and a chat box feature is recommended. ${ }^{[32]}$ Additionally, national and international educational collaboration can be pursued on online platforms to improve the existing educational efforts.

\section{Future research opportunities}

The risk of thrombotic complications (symptomatic acute pulmonary embolism, deep vein thrombosis, ischemic stroke, myocardial infarction or systemic embolism) in patients suffering from COVID-19 and admitted to the ICU has been reported as 31\%, which reinforces the need for strict application of pharmacological prophylaxis and serves as a point of future research for interventional radiologists. ${ }^{[33]}$ We need to understand the mechanism behind the increasing rate of these complications and develop appropriate guidelines for their management. 


\section{Conclusion}

The COVID-19 pandemic has posed unprecedented challenges to public health systems and hospital services throughout the world. With adequate preparation and workflow modifications, IR teams can overcome the unique challenges of safety while providing adequate and efficient high-quality patient care. In this rapidly evolving pandemic, we have provided a framework based on global experiences that need to be adapted by the IR community in India.

\section{Financial support and sponsorship}

Nil.

\section{Conflicts of interest}

There are no conflicts of interest.

\section{References}

1. MoHFW I Home [Internet]. Available from: https://www.mohfw. gov.in/. [Last cited on 2020 May 30].

2. Mossa-Basha M, Meltzer CC, Kim DC, Tuite MJ, Kolli KP, Tan BS. Radiology department preparedness for COVID-19: Radiology scientific expert panel. Radiology 2020:200988. doi: 10.1148/ radiol.2020200988.

3. Shereen MA, Khan S, Kazmi A, Bashir N, Siddique R. COVID-19 infection: Origin, transmission, and characteristics of human coronaviruses. J Adv Res 2020;24:91-8.

4. Zhong NS, Zheng BJ, Li YM, Poon LLM, Xie ZH, Chan KH, et al. Epidemiology and cause of severe acute respiratory syndrome (SARS) in Guangdong, People's Republic of China, in February, 2003. Lancet 2003;362:1353-8.

5. de Wilde AH, Snijder EJ, Kikkert M, van Hemert MJ. Host factors in coronavirus replication. Curr Top Microbiol Immunol 2018;419:1-42.

6. Guo YR, Cao QD, Hong ZS, Tan YY, Chen SD, Jin HJ, et al. The origin, transmission and clinical therapies on coronavirus disease 2019 (COVID-19) outbreak- An update on the status. Mil Med Res 2020;7:11.

7. National Health Commission of People's Republic of China. Pneumonia diagnosis and treatment of 2019-nCoV infection from Chinese NHC and CDC 2020. [Internet]. Available from: http:// www.nhc.gov.cn/xcs/zhengcwj/202001/4294563ed35b43209b317 39bd0785e67/files/7a9309111267475a99d4306962c8bf78.pdf. [Last cited on 2020 May 17].

8. van Doremalen N, Bushmaker T, Morris DH, Holbrook MG, Gamble A, Williamson BN, et al. Aerosol and surface stability of SARS-CoV-2 as compared with SARS-CoV-1. N Engl J Med 382;2020:1564-7.

9. Li Q, Guan X, Wu P, Wang X, Zhou L, Tong Y, et al. Early transmission dynamics in Wuhan, China, of novel coronavirus-infected pneumonia. N Engl J Med 2020;382:1199-207.

10. $\mathrm{Wu} \mathrm{Z,} \mathrm{McGoogan} \mathrm{JM.} \mathrm{Characteristics} \mathrm{of} \mathrm{and} \mathrm{important} \mathrm{lessons}$ from the coronavirus disease 2019 (COVID-19) outbreak in China: Summary of a report of 72314 cases from the Chinese Center for Disease Control and Prevention. JAMA 2020;323:1239-42.

11. Guan WJ, Ni ZY, Hu Y, Liang WH, Ou CQ, He JX, et al. Clinical characteristics of coronavirus disease 2019 in China. N Engl J Med 2020;382:1708-20.

12. Wong HYF, Lam HYS, Fong AHT, Leung ST, Chin TWY, Lo CSY, et al. Frequency and distribution of chest radiographic findings in COVID-19 positive patients. Radiology 2019:201160. doi: 10.1148/radiol. 2020201160.

13. Simpson S, Kay FU, Abbara S, Bhalla S, Chung JH, Chung M, et al. Radiological Society of North America Expert consensus statement on reporting chest CT findings related to COVID-19. Endorsed by the Society of Thoracic Radiology, the American College of Radiology, and RSNA. Radiol Cardiothorac Imaging 2020;2:e200152. doi: 10.1148/ryct. 2020200152.

14. The updated case definitions and contact-categorisation. National Centre for Disease Control. Available from: https://ncdc.gov.in/ WriteReadData/1892s/89568514191583491940.pdf. [Last cited on 2020 May 17].

15. COVID-19 | Indian Council of Medical Research I Government of India [Internet]. Available from: https://main.icmr.nic.in/content/ covid-19. [Last cited on 2020 May 17].

16. Kucirka LM, Lauer SA, Laeyendecker O, Boon D, Lessler J. Variation in false-negative rate of reverse transcriptase polymerase chain reaction-based SARS-CoV-2 tests by time since exposure. Ann Intern Med 2020:M20-1495. doi: 10.7326/M20-1495.

17. Aarogya Setu Mobile App. MyGov.in [Internet]. Available from: https://mygov.in/aarogya-setu-app/. [Last cited on 2020 Jun 21].

18. Cook TM. Personal protective equipment during the coronavirus disease (COVID) 2019 pandemic - A narrative review. Anaesthesia 2020;75:920-7.

19. Updated Additional Guidelines on Rational Use of Personal Protective Equipment. Available from: https://www.mohfw.gov. in/pdf/Updated Additional guidelines onrationaluse ofPersonal ProtectiveEquip mentsetting approachfor Healthfunctionaries workinginnonCOVID19areas.pdf. [Last cited on 2020 May 30].

20. STANDARD OPERATING PROCEDURE (SOP) for extended use of N95 mask for personal safety of Health Care Workers (HCW) at AIIMS [Internet]. Available from: https://www.aiims.edu/en/ notices/notices.html?id=10444. [Last cited on 2020 May 18]

21. (No Title) [Internet]. Available from: https://apps.who.int/iris/ bitstream/handle/10665/150117/WHO_HIS_SDS_2015.3_eng. pdf?sequence $=1$. [Last cited on 2020 May 18].

22. Poston JT, Patel BK, Davis AM. Management of critically ill adults with COVID-19. JAMA 2020: 18:1839- 41. doi: 10.1001/jama. 2020.4914.

23. Society of Interventional Radiology- Aerosol generating procedures clinical notification [Internet]. Available from: https://www.sirweb.org/practice-resources/covid-19-resources/ covid-19-clinical-notification-3-26-20/. [Last cited on 2020 May 18].

24. Too CW, Wen DW, Patel A, Abdul Syafiq AR, Liu J, Leong S, et al. Interventional radiology procedures for COVID-19 patients: How we Do it. Cardiovasc Intervent Radiol 2020;43:827-36.

25. Wong J, Goh QY, Tan Z, Lie SA, Tay YC, Ng SY, et al. Preparing for a COVID-19 pandemic: A review of operating room outbreak response measures in a large tertiary hospital in Singapore. Can J Anesth 2020;67:732-45.

26. Welch D, Buonanno M, Grilj V, Shuryak I, Crickmore C, Bigelow AW, et al. Far-UVC light: A new tool to control the spread of airborne-mediated microbial diseases. Sci Rep 2018;8:2752.

27. Ierardi AM, Wood BJ, Gaudino C, Angileri SA, Jones EC, Hausegger K, et al. How to handle a COVID-19 patient in the angiographic suite. Cardiovasc Intervent Radiol 2020;43:820-6.

28. Society of Interventional Radiology- Covid-19 postponed procedures [Internet]. Available from: https://www. sirweb.org/practice-resources/toolkits/covid-19-toolkit/ covid-19-postponed-procedures/. [Last cited on 2020 May 18].

29. Society of Interventional Radiology- COVID-19 Grant Opportunity [Internet]. Available from: https://www.sirfoundation. org/grants_awards/covid-19?utm_content=buffer09e93\&utm medium=social \&utm_source=facebook.com\&utm_ 
campaign=buffer. [Last cited on 2020 May 21].

30. Paranjpe I, Fuster V, Lala A, Russak A, Glicksberg BS, Levin MA, et al. Association of treatment dose anticoagulation with in-hospital survival among hospitalized patients with COVID-19. J Am Coll Cardiol 2020;76:122-4.

31. Caring for our caregivers during COVID-19 | American Medical Association [Internet]. Available from: https:// www.ama-assn.org/delivering-care/public-health/ caring-our-caregivers-during-covid-19. [Last cited on 2020 May 18].

32. Alvin MD, George E, Deng F, Warhadpande S, Lee SI. The impact of COVID-19 on radiology trainees. Radiology 2020:201222. doi: 10.1148/radiol. 2020201222.

33. Klok FA, Kruip MJHA, van der Meer NJM, Arbous MS, Gommers DAMPJ, Kant KM, et al. Incidence of thrombotic complications in critically ill ICU patients with COVID-19. Thromb Res 2020;191:145-7. 